\title{
OBSERVATIONS OF THE WHITE-LIGHT CORONA BY ROCKET
}

\author{
by R. Tousey \\ (E. O. Hulburt Center for Space Research \\ U. S. Naval Research Laboratory, Washington D. C., 20390, U. S A.) (1) ${ }^{(2)}$
}

RÉsumt. - Une fusée Aerobee a emporté dans l'espace le 28 juin 1963 un coronographe de Lyot employant un disque d'occultation à bord dentelé extérieur. Entre 131 et $204 \mathrm{~km}$ d'altitude, on a obtenu 23 photographies en lumière blanche avec des temps de pose compris entre 1 et 56 secondes. La couronne a été photographiée depuis 3,5 jusqu'à 10 rayons solaires du centre. La forme de la distribution radiale de l'intensité coronale est la même que celle que l'on détermine pendant les éclipses totales; mais l'intensité elle-même est deux à trois fois plus grande, ce qui semble indiquer qu'une quantité de lumière notable est diffusée dans un faible angle solide par de la matière située entre le soleil et la terre, matière qui n'est pas illuminée pendant une éclipse totale. Un jet coronal a été mesuré jusqu'à $10 R_{\odot}$ environ, avant qu'il se fonde dans la couronne. Des passages de particules à mouvement lent dans l'espace sont visibles sur la plupart des photographies.

ABstraOT. - A Lyot coronagraph with a saw-toothed external occulter was flown in an Aerobee rocket on June 28, 1963. Twenty-three white-light photographs, with exposure times from 1 to 56. seconds were secured at altitudes from $131 \mathrm{~km}$ to $204 \mathrm{~km}$. The corona was recorded from 3.5 to 10 solar radii from the Sun's center. The coronal brightness function followed distributions determined during total solar eclipses; however, the brightness level was two to three times greater, suggesting that a significant quantity of light originates from small-angle forward-scattering by material between the earth and the sun, which is not illuminated during a total eclipse. One coronal streamer was recorded to about ten radii, before disappearing into the corona. Trails of slow-moving particles in space are conspiouous in most of the photographs.

Резюме. - Ракета Aerobee вынесла в пространство 28 ионя 1963 г коронограф Лио, использующий для сокрытия диск с зубчатым внешним краем. На высоте между 131 и 204 км были получены 23 фотографии в белом свете с выдержками заключенными между 1 и 56 секундами. Корона была с фотографирована начиная от 3,5 и до 10 солнечных радиусов от центра. Вид радиального распределения корональноћ интенсивности тот-же, что определяют во время полных солнечных затмений, но сама интенсивность от двух до трех раз больше, что по-видимому указывает на то, что значительное количество света рассеяно в небольшом телесном угле веществом, находящимся между Солнцем и Землей, вещество, которое не освещено во время полного затмения. Ыыла измерена корональная струя приблизительно до $10 \mathrm{R} \odot$ до ее растворения в короне. На большинстве фотографий видимы пересечения пространства медленными частицами.

\section{INTRODUOTION}

Although the coronagraph devised by LYoT (1930) makes it possible to observe the inner, emission line corona at any time when the sky is clear, little of the outer corona can be detected because of the presence of the bright sky. With polarization photometers, the $\mathrm{K}$-corona can be recorded somewhat farther and streamers can be followed to about three solar radii $\left(\mathbf{R}_{\odot}\right)$ from the Sun's center (WréRICK and AxTeLL, 1957 ; DoLLFUs, 1963). Until recently, however, a total solar eclipse has been required in order to see the outer corona. Even then the sky is not completely dark, and better results are obtained from aircraft

(1) Work supported in part by the National Aeronautics and Space Administration.

(2) Sponsored jointly by the Office of Naval Research and the National Science Foundation.
(BLACKWELL, 1954) or balloons (NEY, 1963 ; GILLETT, Stern and NEY, 1964).

In principle, it is possible to construct a coronagraph, so free from stray light thatit would reveal the entire corona if placed at an altitude above the Rayleigh sky. The first attempt (NEwKIRK and EDDY, 1962), using an externally occulted Lyot coronagraph lifted to 80,000 feet with a balloon, failed because of excessive stray light originating from the edge of the occulter. A similar instrument, but with an improved occulter, flown by the Naval Research Laboratory (NRL) in an Aerobee rocket on June 28, 1963, was successful in producing the first photographs of the outer corona to be made without a total eclipse (Koomen, PUroell, Sear and Tousey, 1964). A photoelectric scanning type coronagraph (CoOPER et al., 1964), flown in the same rocket, telemetered to ground a pair of pictures in radial and tangen- 
tial polarizations. These instruments were constructed as part of a program in preparation for the flight of a coronagraph in the second orbiting solar observatory (OSO-B) of the National Aeronautics and Space Administration (NASA). As has just been reported by NEwKIRK, the balloon-borne coronagraph of NEwKIRK and BoHIIN (1963), with an improved external occulting system was flown successfully on March 5, 1964, and recorded the corona from $R=1.8$ to $5.25 R_{\odot}$.

\section{The Coronagraphs.}

The rocket-coronagraphs were basically the same as the Lyot coronagraph, but with an external occultor placed $50 \mathrm{~cm}$ in front of the objective lens, of focal length $30 \mathrm{~cm}$ and diameter $25 \mathrm{~mm}$. Two instruments were mounted within a single case, as shown in Figure 1, each with its own occulter supported by an arm attached to a spar. By means of a biaxial pointing control, the entire unit was kept pointed at the Sun to within 1 arc minute during the upper part of the trajectory. In one instrument the corona was recorded on photographic film ; in the other it was scanned and telemetered, first in radial and second in tangential polarization. The field covered was from 3.5 to $10 R_{\odot}$ from the Sun's center.

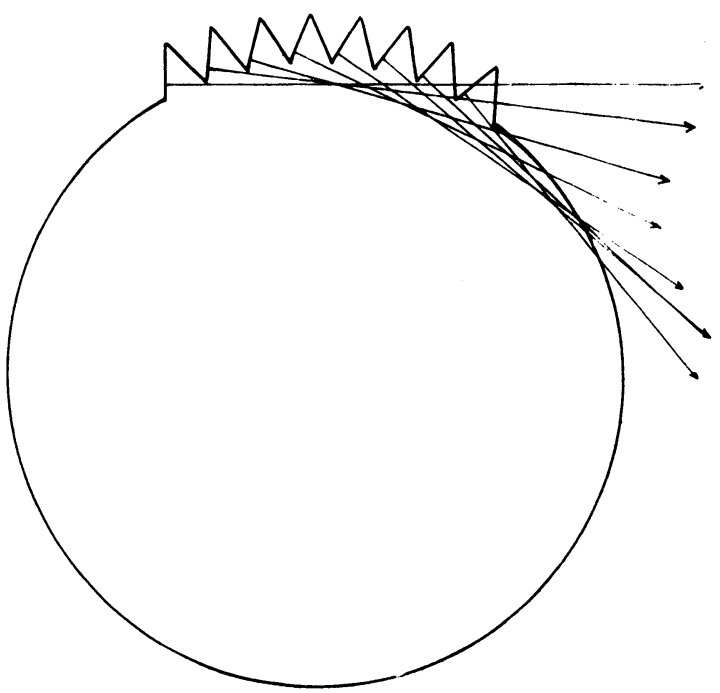

Fia. 2. - Diffraction of parallel light by a toothed occulter. The beam is incident perpendicularly to the plane of the figure and the directions of the diffracted rays are shown in projection on the plane of the figure.

The key to the operation of this coronagraph lies in the occulter. The best arrangement is a multiple-disc occulter, consisting of three discs with smooth edges placed in tandem, of sizes such that the second blocks the light from the edge of the first, and so forth. At the beginning, consideration was given to the use of a multiple-disc occulter but it was decided that it would be too difficult to stow the spar and the three discs during take off and then to place them in precisely the correct positions during flight. The optical characteristics of a triple occulter have been independently investigated by GILLETT (1961) and by NEwKIRK and BoHlin $(1963,1964)$. The latter found it possible in this way to reduce the stray light to about $1^{-9} \mathrm{~B}_{\odot}$ (mean solar brightness), in a coronagraph for a balloon, as reported by NEWKIRK.

The occulter used for the rocket coronagraph was the toothed disc of PURCELL and Koomen (1962), whose operation is illustrated in Figure 2. Each tooth, ideally, consists of a pair of straight edges. Parallel light, incident normally to the plane of the figure, is diffracted at right angles to each edge. The result is a hollow cylindrical envelope, with all the flux diffracted outside; no flux is sent inside, where the objective lens is located. For this condition to be realized, however, the edge must be absolutely clean and free from irregularities, and the intersections must be sharp.

The effectiveness of the toothed disc can be seen from Figure 3, which shows a smooth disc and a disc with 240 teeth, each illuminated by parallel light, and photographed with a camera whose lens occupied the position of the coronagraph objective. Equal exposure times were given. It was found almost impossible to eliminate all scattered light, in spite of rigorous cleaning, but the edge of the smooth disc shines brightly by comparison.

The coronagraph system was tested in an evacuated tank, so as to remove all light scattered by the air. With an artificial sun in operation, the stray light was found to be about $10 \%$ of the brightness of the corona, as tabulated by ALLEN (1955) for quiet solar conditions.

\section{RhSULts}

With the photographic coronagraph, twentythree exposures were obtained with exposure times between 1 and 56 seconds, using Eastman Kodak type 1-D emulsion. The altitude ranged from $131-\mathrm{km}$ to $204 \mathrm{~km}$. Four photographs are reproduced in Figure 4. Since the coronagraph was focussed for infinity, the shadows cast by the occulter and supporting arm are greatly out of focus. Although the coronagraph remained constantly pointed at the Sun, it rotated, slowly, 
Fig. 1 - Rocket coronographs, insstalled in biaxial pointing control and occupying the forward section of an Aerobee-150 rocket. The external occulters are mounted on a spar which is placed in position during flight, after removal of the rocket nose cone.
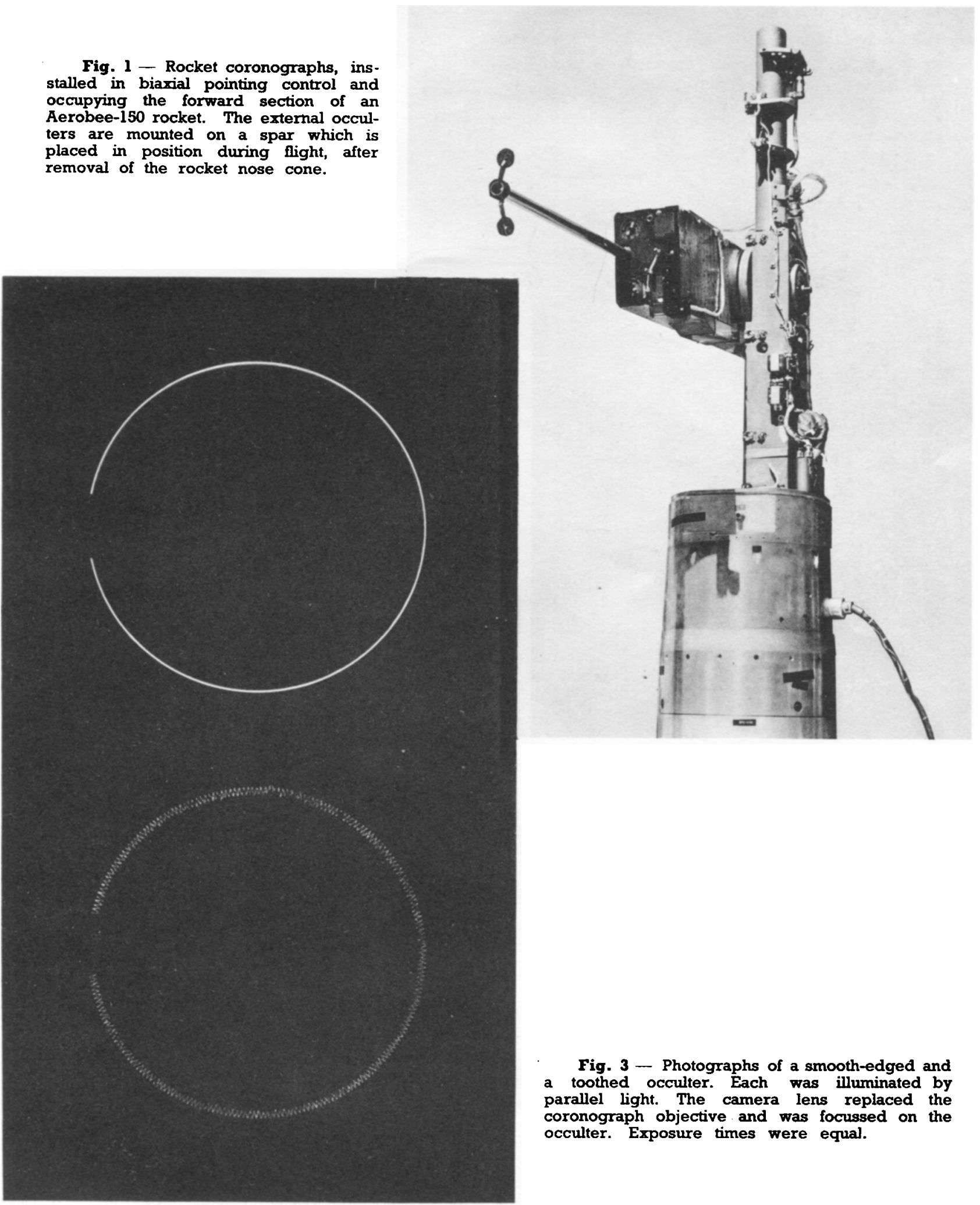

Fig. 3 - Photographs of a smooth-edged and a toothed occulter. Each was illuminated by parallel light. The camera lens replaced the coronograph objective and was focussed on the occulter. Exposure times were equal. 


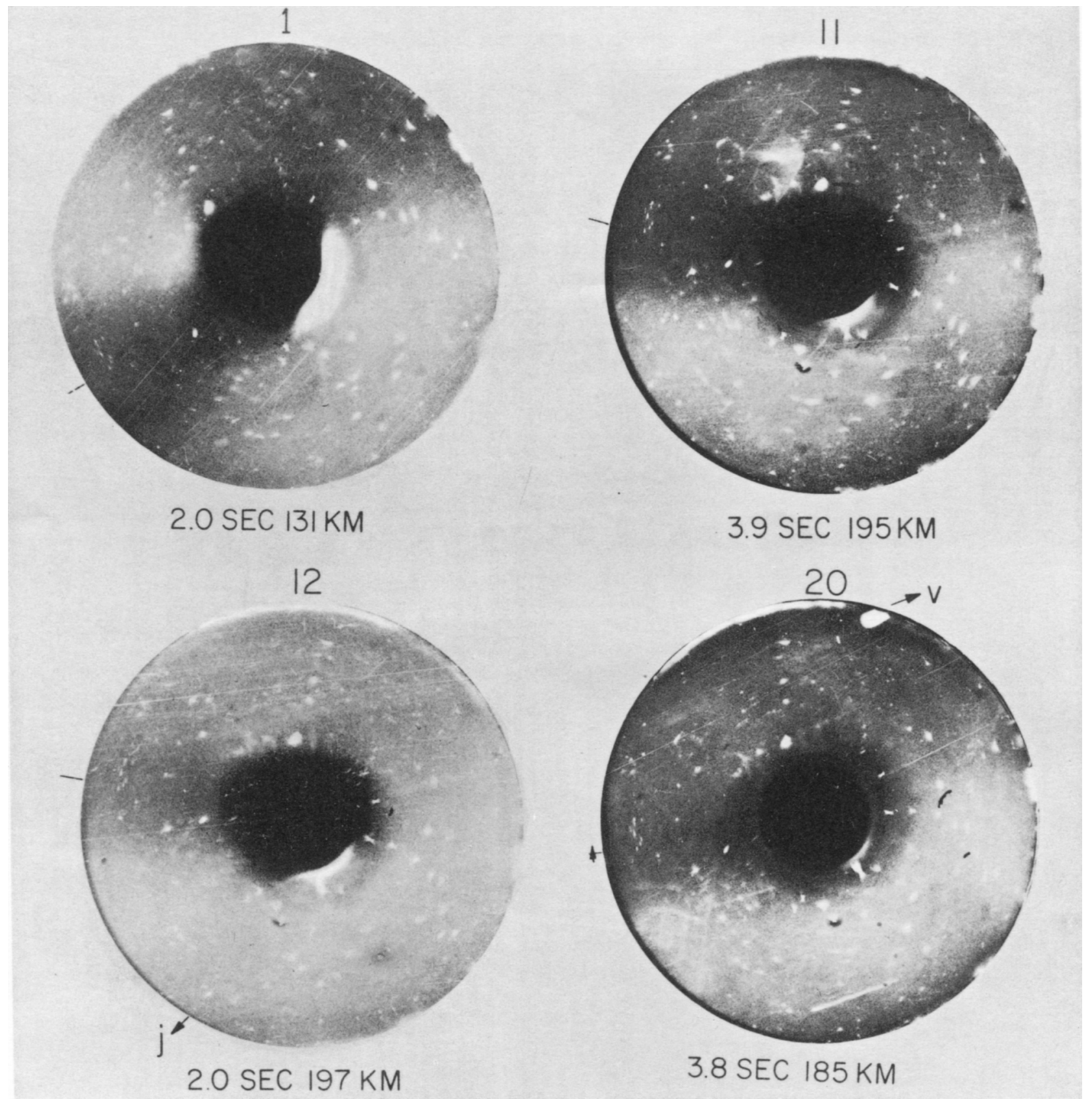

Fig. 4 - Coronal photographs made on June 28, 1963 from an Aerobee-150-rocket; altitudes and exposure times are shown. Solar north is at the top and west at the right. The short mark, located at the center of the shadow of the arm which carried the occulter, gives the rotational position of the coronograph for each exposure. 


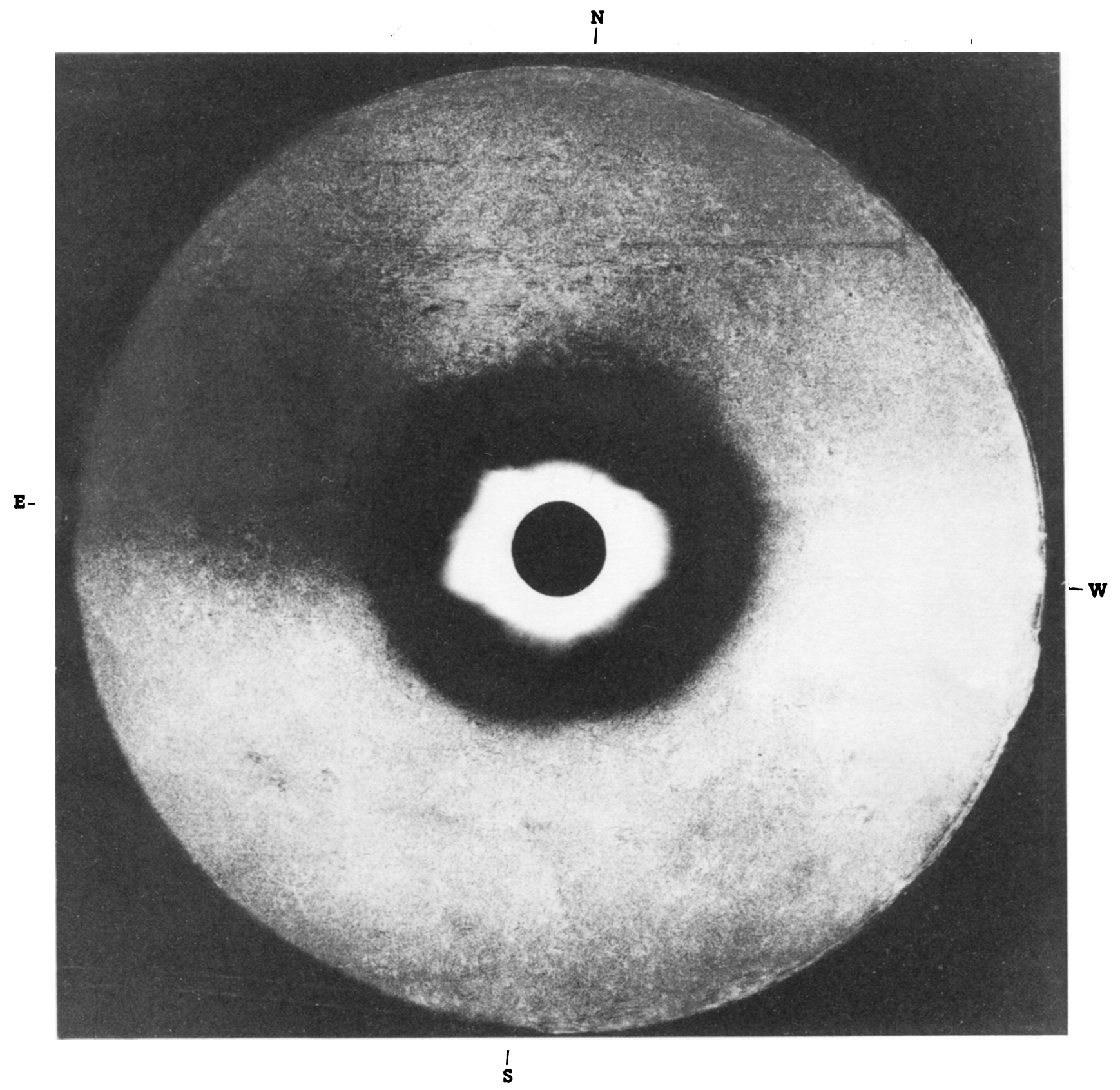

Fig. 5 - Coronal Exposure No. 11 with all artifacts removed by retouching. A photograph of the corona during the July 20, 1963 eclipse (courtesy High Altitude Observatory) has been introduced at the proper scale and orientation. 
$\mathbf{N}$

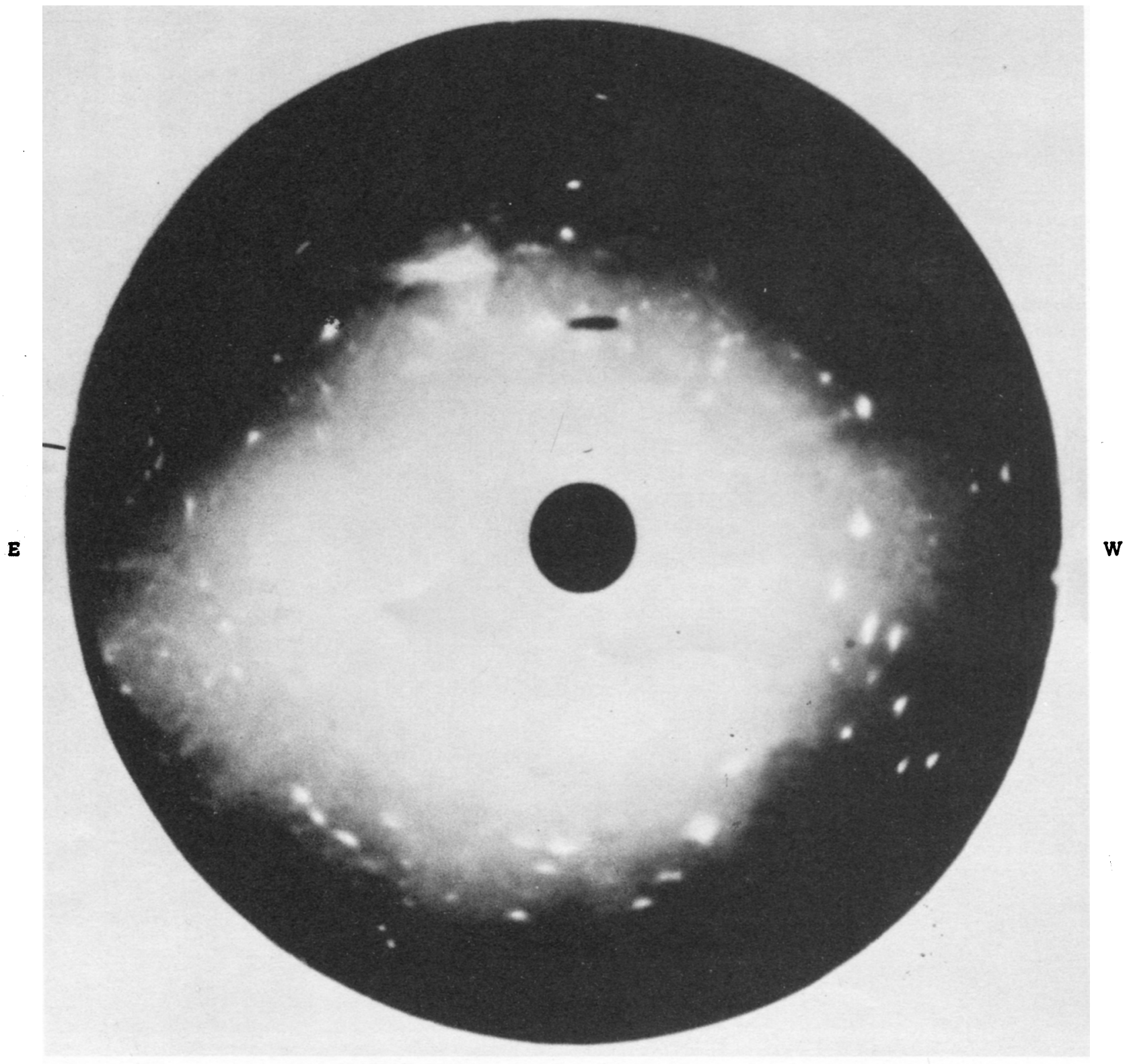

S

Fig. 6 - The corona, reprinted from Exposure 11 with compensation for the radial speed function of the camera. The opaque central spot shows the size of the sun.

TOUSEY $-\mathrm{VI}-\mathrm{I}$ 
around the direction to the Sun, owing to the precession of the rocket. The rotation was very little during these short exposures, but was considerable during long exposures and changed during the sequence. As shown in Figure 4, the pictures have been oriented alike in the sky, with solar north at the top and east at the left. The position of the arm, indicated by the short line, shows the rotation position of the coronagraph for each picture.

There are a number of spurious effects in these photographs. The bright lune close to the edge of the occulter was caused by a slight mispointing, with the result that some scattered light reached the objective from the edge of the occulter. The pointing improved during flight, and was nearly perfect by Exposure 20. The many bright spots, scattered over the field, rotate with the picture, and are attributed to dirt on a surface of the field lens, which was somewhat out of focus. This is believed to have been produced by vibration during launch, since it was not present during laboratory tests. The bright streak at the lower edge of Exposure 20, however, was caused by a small object crossing the field of view and glowing brightly because of sunlight scattered at an angle of about $2^{\circ}$. Many such trails were present. They are attributed to slow-moving particles in the neighbourhood of the rocket.

The general background, however, is ascribed to the white light corona. Figure 5 is another print of Exposure 11, with all artifacts removed by retouching. A photograph of the solar corona is introduced at the center at the same scale and orientation. This was obtained by Frror and colleagues (1963) during the total eclipse of July 20, 1963, twenty-two days after the rocket photographs.

The corona shows a brighter region at the west, and also at the east, though in the latter position it was largely obscured by the arm. This is typical of the F-corona, of course. Radially, however, the corona seems to be uniform in brightness. This was exactly the way it should appear with this coronagraph because of vignetting produced by the external occulter. This gave rise to a radial speed function which increased outward rather rapidly, and in such a way that the product of the coronal brightness function and the occulter vignetting function was nearly constant from $\mathrm{R} / \mathrm{R}_{\odot}=3.5$ to 10 .

In Figure 6 another reproduction of Exposure 11 is shown. This was made by Koomen and SeAL, by projecting Exposure 11 back through the coro- nagraph and re-photographing in such a way as to remove the vignetting function. The region inside $R / R_{\odot}=3.5$ was filled in so as to show the Sun's disc at its proper size. The process was not exact, but the result was a photograph more nearly of the usual kind.

Because of the rotation of the instrument around the direction to the Sun during most of the exposures, there was little hope of detecting long, sharply defined streamers of the type sometimes seen at totality when the Sun is quiet. One, however, appears to be present, and can be seen in all four exposures. It is located on the west and makes an angle of about $15^{\circ}$ to the equator. Projected toward the Sun, it reaches a point a little north of its center. This streamer was not visible in any of the other exposures, either because of excessive rotation, or insufficient exposure time. These four exposures show clearly that this streak remained stationary in the sky when the instrument rotated, and therefore was a coronal streamer rather than an instrumental defect or a particle trail. It can be followed to $R / R_{\odot}=10$. 'Its position seems reasonable and might be related to the edge of the coronal brush, photographed during the July 20, 1964 eclipse. Since the intervening period was 22 days, a perfect correspondence would not be expected.

Exposures 1, 11 and 20 were reduced to intensities by application of the methods of photographic photometry. Averaged isophots are shown in Figure 7. Since Exposure 1 was made with the

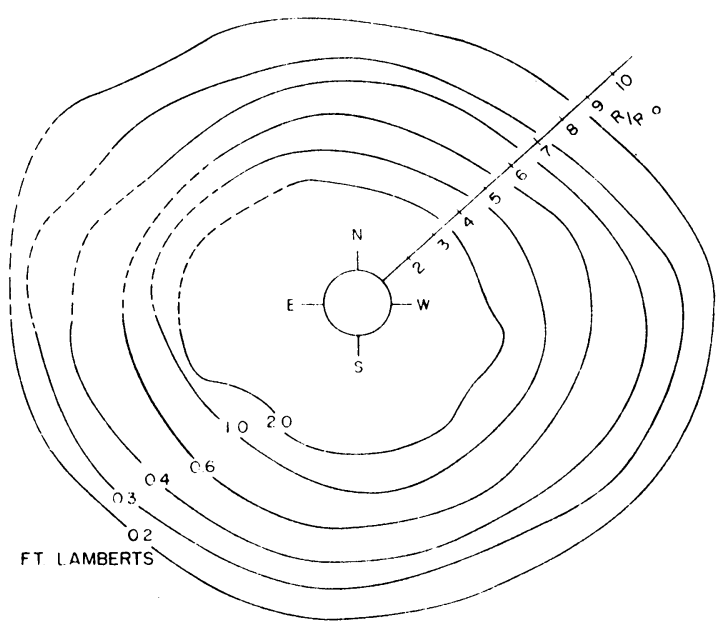

Frg. 7. - Isophots showing the brightness of the corona, as determined from Exposures 1, 11 and 20. Brightness may be converted to fractions of the mean solar brightness by multiplying by $1.4 \times 10^{-8}$. June 28, 1963, Aerobee NE 3.129. 
arm $40^{\circ}$ away from its position in Exposure 11, it was possible to fill in the shadow region. Brightness values, given in $\mathrm{ft}$. Lamberts, can be converted to fractions of $B_{\odot}$ by multiplying by $1.4 \times 10^{-9}$.

Curves of coronal brightness versus $\mathbf{R} / \mathbf{R}_{\odot}$, taken from the isophot plot, are shown in Figure 8 for the equatorial and the North and South Polar regions. It is difficult to estimate the accuracy. of these results, because of the presence of so many artifacts, and the possibility that the stray light was not as low during flight, as when measured in the laboratory. Plotted also are data obtained during the July 20, 1963 solar eclipse by GIILETT, SteIn and NeY (1964) by direct photography from a balloon at 110,000 feet.

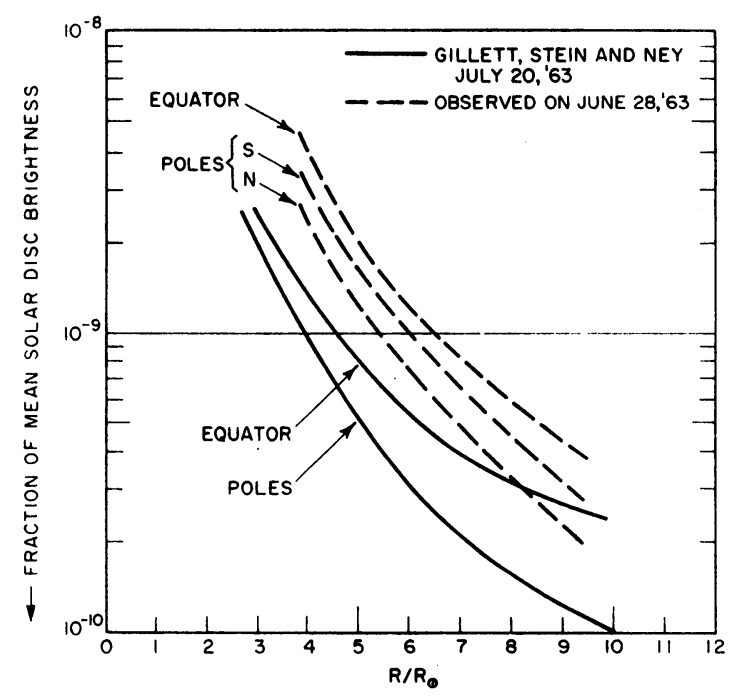

Fic. 8. - The distribution of brightness in the corona on June 28, 1963, determined from the isophots of Fig. 7, and data obtained during the July 20, 1963, eclipse by Gillett, Stein and Ney (1964).

The rocket and eclipse data are in fair agreement in general. From the rocket photographs it appeared that the brightness over the Sun's South Pole was greater than over the North. There is little reason to believe that this was correct, since no difference would be expected so far from the limb, where the corona is mainly zodiacal in origin. None was observed by GILLETT et al., but from $\mathrm{R} / \mathrm{R}_{\odot}=1.2$ to 1.6 they found the region over the South Pole to be weaker than that over the North.

The coronal brightnesses, as observed from the rocket, are about three times greater than those recorded during total solar eclipse at $R / R_{\odot}=4$; this difference decreases to a factor of about two at $R / R_{\odot}=10$. The brightness difference is thought to be greater than experimental error. It is attributed to a contribution to the zodiacal light made by material rather close to the earth. There is an important optical difference between observations obtained with the rocket-coronagraph and those made during a total eclipse. In the former, the entire path through which the corona must be observed is illuminated by full sunlight; in the latter, a large part of the optical path is wholly or partially screened from sunlight by the Moon. During totality, for the range $R / R_{\odot}=5$ to 10 , the region completely screened extends some $1000 \mathrm{~km}$ away from the earth, and partial screening continues to 15 earth radii or more.

The increased brightness observed when this region is not dark, suggests that there is sufficient meteoritic and other material within a few Earth radii to double the F-coronal brightness. Observations of the corona made with balloon and rocket-borne coronagraphs from the beginning of a solar eclipse, through totality and to the end should provide a method of determining the contribution to the zodiacal light from material located at different distances from the earth. Very careful calibration would be required, however, in order to derive accurate results.

Coronal brightness data were also obtained with the photoelectric coronagraph flown on June 28, 1963 in the same rocket. Within the time available two coronal scans from $R / R_{\odot}=4$ to 11 , were recorded, one in radial and another in tangential polarization. The average brightness was twice greater than the photographic result at $R / R_{\odot}=10$, but became equal at $R / R_{\odot}=4$. The polarization data were not in agreement with results obtained during totality. At the inner edge of the region scanned, the tangential component was more intense than the radial, as it should be. But from $R / R_{\odot}=5$ to 11 there appeared to be a small amount of negative polarization, of the order of $15 \%$. No explanation for this has been found. Since both the increased brightness over the photographic results and the negative polarization occurred over the outer part of the field, a common cause is suspected. The most likely explanation is that some change in the stray light characteristics of the instrument took place during the powered portion of the flight.

\section{Manuscrit reçu le $1^{\mathrm{er}}$ mars 1965.}




\section{REFERENCES}

Alume C. W., 1955, "Astrophysical Quantities", Univ. of London.

Blackwhlu D. E., 1955, Mon. Not. Roy. Astron. Soc., 115, 44.

Cooper H. W., Detwiner C. R., Koomen M. J., Packer D. M., Purcell J. D., Sead R. T. Jr. and Toushy R., 1964, private communication.

Dollrus A., 1963, " The Solar Corona ", J. W. Evans, Ed., Academic Press, New York, 243-246.

Finor J. W., 1963, High Altitude Observatory, Boulder, Colorado, private communication.

Grumte F. C. Stein W. A. and Ney E. P., 1964, Ap. J., 140, 242.
GmLETr F., 1961, Summary Report, University of Minnesota.

Koomen M. J., Purcell J. D., Seal R. T. Jr. and Tousey R., 1964, J. Opt. Soc. Am., 54, 1409.

Lуот B., 1930, Compt. Rend., 191, 834.

NEwkIRK G. Jr. and EDDy J. A., 1962, Sky and Telescope, 24, 77.

NewkIRK G. Jr. and BoHIIN D., 1963, Applied Optics, 2, 131 ; 1964, Applied Optics, 3, 543 ; sky and Telescope, 28, 16.

NFx E. P., 1963, Sky and Telescope, 25, 1.

Purchll J. D. and Koomen M. J., 1962, J. Opt. Soc. Am., 52, 596 ; Sky and Telescope, 24, 197.

Wleriok G. and Axtell J., 1957, Ap. J., 126, 253. 